\section{Evaluation of antifungal effect of gaseous ozone in a meat processing plant}

\author{
Lisa Vallone, Simone Stella
}

Dipartimento di Scienze Veterinarie per

la Salute, la Produzione Animale e la Sicurezza Alimentare, Università degli

Studi di Milano, Italy

\section{Abstract}

Ozone is already known as effective food/environmental disinfection agent, thanks to its oxidative action towards microbial cell components. Bactericidal effect of ozone is well documented, while data concerning its inhibitory activity towards fungi are still ambiguous. Our study aims to evaluate the antimicrobial activity of gaseous ozone towards potentially contaminant fungi in a meat production plant in real working conditions. $\mathrm{M}_{2}$ and $\mathrm{M}_{5} \mathrm{~S}_{5}$ plates were inoculated with Aspergillus niger, Penicillium roqueforti, Mucor racemosus, Saccharomyces cerevisiae strains and positioned in a deboning room, where gaseous ozone was dispensed throughout the night (until a maximum concentration of $20 \mathrm{ppm}$ ). Nine different points were chosen, based on height and distance from the ozone dispenser. After the treatment, the presence of strains growth was evaluated. Gaseous ozone did not show any inhibitory activity against mould strains, as optimum growth during all the trials was observed. An appreciable and constant microbicidal effect against $S$. cerevisi$a e$ was evidenced, with a mean value of $2.8 \mathrm{Log}$ reduction. Our results suggest the importance of the definition of environmental and technical use conditions in order to optimise the antimicrobial efficacy of ozone in real working situations in food industries.

\section{Introduction}

Ozone is a gas that is naturally present in the stratosphere; it is water-soluble and has a high oxidative power. The latter characteristic has been positively considered since ozone was discovered by Van Marum in 1783 and it has been used thanks to its bactericidal, fungicidal and virucidal activities. Ozone toxicity towards cells is due to its decomposition to oxygen; during this transformation, direct and indirect (via hydroxyl radicals formation) substrates' oxidation and peroxidation take place, leading to the alteration of both the structure and the functionality of biomolecules (Khadre et al., 2001; Laisk et al., 1989; Sarti et al., 2002; Staehelin and Hoigne, 1985).

Thanks to its useful properties, ozone is largely applied in several industrial processes. In particular, it is used for disinfection of water (bottled water, potable water networks and swimming pools), air, wood, several foodstuffs (in particular fruits and vegetables) and surfaces that are intended to be in direct contact with food. The application of ozone does not leave any residue in the environment or on treated substrates, thanks to its natural transformation into oxygen. It has been defined as a generally recognised as safe agent by the USA Food and Drug Administration, but the toxicity towards workers must be taken into account, so safety measures must be carefully applied.

The antimicrobial efficacy of ozone is influenced by environmental conditions, mainly temperature, humidity and $\mathrm{pH}$ values. The best microbicidal action is obtained in environments with low temperatures and presence of water or high relative humidity.

Sensitivity of bacteria to the action of ozone is variable: Gram positive bacteria are more susceptible than Gram negative bacteria, due to the different cell wall composition and the resulting sensitivity to lipid peroxidation, while bacterial spores are strongly resistant to the action of ozone (Khadre et al., 2001; Khadre and Yousef, 2001; Kim et al., 1999). The mechanism of virus inactivation is not completely cleared, but it is known that higher ozone concentrations are required to exert a virucidal effect (Kim et al., 1999). As regards fungi, several authors evidenced the efficacy of gaseous ozone as inactivating agent against spores. Since 1951, moulds growth prevention on cheese surfaces during ripening was demonstrated with a dose equal to $1 \mathrm{ppm}$ (CNSA, 2010). A study conducted on Cheddar cheese in Canada (Gibson et al., 1960) showed that the exposure to an ozone concentration of 3-10 ppm resulted in moulds darkening on cheese surface, associated to a $96 \%$ reduction in air moulds concentration in ripening rooms. The application of lower ozone concentrations (0.2-0.3 ppm) was sufficient to obtain a significant reduction of moulds, with no modification of sensory characteristics of cheese. During the $70 \mathrm{~s}$, these findings were confirmed, identifying a $10 \mathrm{ppm}$ ozone concentration as efficient for spore inactivation (CNSA, 2010). The inhibitory activity of ozone against yeasts has been evidenced by several authors, both in vitro and on different foods. Yeasts are naturally more resistant than bacteria to the action of ozone, thanks to their thicker cell wall, but they are clearly more susceptible than moulds (Kim et al., 1999; Moore et al., 2000). A different sensitivity has been observed among different yeast species; for example Candida spp. and Saccharomyces spp. are usually rapidly inhibited by ozone, while Debaryomyces spp.
Correspondence: : Lisa Vallone, Dipartimento di Scienze Veterinarie per la Salute, la Produzione Animale e la Sicurezza Alimentare, Università degli Studi di Milano, via Grasselli 7, 20137 Milano, Italy.

Tel. +39.02.50318511 - Fax: +39.02 .50318501 .

E-mail: lisa.vallone@unimi.it

Key words: Gaseous ozone, Mould, Raw meat, Saccharomyces cerevisiae.

Conflict of interests: the authors declare no potential conflict of interests.

Received for publication: 11 May 2013

Revision received: 30 November 2013.

Accepted for publication: 1 December 2013.

This work is licensed under a Creative Commons Attribution 3.0 License (by-nc 3.0).

(C) Copyright L. Vallone and S. Stella, 2014 Licensee PAGEPress, Italy

Italian Journal of Food Safety 2014; 3:1680 doi:10.4081/ijfs.2014.1680

is strongly resistant (Naitoh, 1993; Pereira et al., 2011; Watanabe et al., 2010).

Considering the growing diffusion of ozone as disinfectant in food industries, this study aimed to evaluate the antimicrobial efficacy of gaseous ozone on potentially contaminating fungi and yeats in a meat deboning and processing plant, in real working conditions.

\section{Materials and Methods}

The efficacy of gaseous ozone was tested in a deboning and processing industry in which vacuum packaged beef meats are produced. The plant is equipped with a centralised, medium frequency corona discharge ozone generator, with a production capacity of $2-20 \mathrm{~g} / \mathrm{h}$. Our evaluation was performed in the deboning room, with a surface of $220 \mathrm{~m}^{2}$ and $4 \mathrm{~m}$ high. Gaseous ozone was supplied by the refrigeration sock ducts for $4 \mathrm{~h}$ during the night (from 11.00 p.m. to 03.00 a.m.); ozone amount was settled to obtain a constant environmental concentration of $20 \mathrm{ppm}$, revealed by a fixed probe.

With the aim of detecting the eventual presence of autochthonous moulds in the environment, the contamination of air was evaluated by keeping open Petri plates with $\mathrm{M}_{2}$ (composition: malt extract $=20 \mathrm{~g} / \mathrm{L}$, yeast extract $=3 \mathrm{~g} / \mathrm{L}$, agar $=15 \mathrm{~g} / \mathrm{L}$ ) and $\mathrm{M}_{5} \mathrm{~S}_{5}$ (composition: malt extract $=50 \mathrm{~g} / \mathrm{L}, \mathrm{NaCl}=50 \mathrm{~g} / \mathrm{L}$, agar= $15 \mathrm{~g} / \mathrm{L}$ ) culture media (Dragoni et al., 1997) in different points of the room for $2 \mathrm{~h}$ before every test session. After the exposition, the plates were collected, transferred to the laboratory and then 
incubated at 25 and $35^{\circ} \mathrm{C}$ for $7-10$ days. For inactivation tests, three moulds strains, namely Mucor racemosus, Penicillium roqueforti and Aspergillus niger, and one yeast strain, i.e. Saccharomyces cerevisiae, from the collection of the Laboratory of Mycology, Department of Health, Animal Science and Food Safety, University of Milan, Italy, were selected, in view of their wide diffusion in meat production and storage plants (Dragoni et al., 1997).

Each strain was grown on $\mathrm{M}_{2}$ (M. racemosus, P. roqueforti and $S$. cerevisiae) or $\mathrm{M}_{5} \mathrm{~S}_{5}$ (A. niger) Petri plates, incubated at $30^{\circ} \mathrm{C}$ for 2 days (S. cerevisiae), $25^{\circ} \mathrm{C}$ for $7-10$ days (M. racemosus and $P$. roqueforti) and $35^{\circ} \mathrm{C}$ for 7-10 days ( $A$. niger). Then, a portion of mycelium from each strain was collected by sterile loop and inoculated onto Petri plates with their specific culture. For $S$. cerevisiae, a suspension with a known concentration (settled by optical density determination with spectrophotometer) was prepared in a diluent solution ( $\mathrm{NaCl} /$ triptone, $0.85 \%$ ); decimal dilutions were inoculated onto $\mathrm{M}_{2}$ Petri plates.

The inactivation of selected fungal strains, inoculated onto culture media and submitted to gaseous ozone was used as index to evaluate the efficacy of ozonation treatment.

After the usual cleaning/disinfection procedures, plates were placed with opened covers, in different points of the deboning room. Three positions (identified as 1,2 and 3) were chosen, based on their distance from the refrigeration sock ducts, and three points at different heights (identified as $\mathrm{L}=10 \mathrm{~cm} ; \mathrm{M}=110 \mathrm{~cm} ; \mathrm{H}=270 \mathrm{~cm}$ ) for each position, in order to evaluate the vertical stratification of ozone, as it is characterised by a high molecular weight and tends to accumulate in lower layers.

After the overnight ozonation, the plates were collected, transported to the laboratory and incubated as described previously. For each selected strain, the same inoculation procedures were performed by Petri plates used as control; after the inoculum process, such plates were refrigerated at $+2^{\circ} \mathrm{C}$ up to collect all exposed test plates, then they were incubated in the same conditions. A total of 6 analytical sessions were performed, during different working weeks; for each session, the test was performed twice.

The inhibitory activity of ozone was evaluated as follows: for moulds, any slow growth, or its absence, was evidenced as difference in mycelium diameter in treated plates when compared with controls. Considering $S$. cerevisiae, the logarithmic decrease of microbial count in treated plates compared with controls was determined.

These data were submitted to a mixed ANOVA by SAS/STAT package version 8.0 (SAS Inst. Inc., Cary, NC, USA). Position and height of sampling points were identified as fixed factors, while analytical session was considered as random factor. A value of $\mathrm{P}<0.05$ was considered statistically significant.

\section{Results}

The evaluation of the concentration of autochthonous moulds in the environment revealed a mean count of 5.6 CFU/plate; moulds belonged to the genera Aspergillus, Penicillium, Alternaria and Mucor; this presence was expected as these genera are extremely common and are widespread in food production environments.

The night distribution of gaseous ozone did not exert any detectable inhibitory action against the selected mould strains in the usual production conditions. An optimal moulds growth on the treated plates was observed, if compared with the control plates in all the analytical sessions. No difference was revealed among the Petri plates placed in different positions or at different heights.

Unlike moulds, an evident microbicide effect against $S$. cerevisiae was observed in all the analytical sessions (Table 1); the statistical analysis revealed a highly significant $(\mathrm{P}<0.01)$ decrease in treated plates against the control. In $96.3 \%$ of the replicates a fall in the counts $>2 \mathrm{Log}$ was detected with a mean value of 2.8 Log (standard deviation=0.6). The inhibitory action was evidenced in all the selected points of the room (Figure 1); no significant difference was detected among the three positions (1-2: $\mathrm{P}=0.91 ; 1-3: \mathrm{P}=0.72 ; 2-3: \mathrm{P}=0.81)$, or the different heights (H-M: $\mathrm{P}=0.91 ; \mathrm{H}-\mathrm{L}$ : $\mathrm{P}=0.64$; $\mathrm{M}-\mathrm{L}$ : $\mathrm{P}=0.57$ ), revealing the uniform distribution of gaseous ozone within the treated environment. Thus, we can suppose that the vertical stratification of ozone, due to its high molecular weight, could be contrasted by constant air flow supplied by the sock ducts placed near the ceiling.

\section{Discussion}

Although the antimicrobial efficacy of ozone has been evidenced by several authors, various studies have already shown a lack of this activity against moulds. Perez et al. (1999) reported an increase in Botrytis cinerea prevalence on

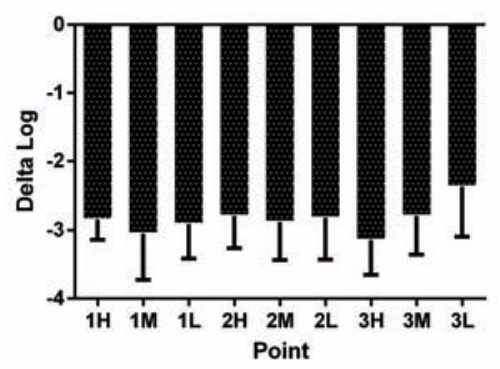

Figure 1. Numbers of $S$. cerevisiae in different points of the deboning room after ozone treatment. Different positions (1-23) and heights $(H=270 \mathrm{~cm}, M=110 \mathrm{~cm}$, $\mathrm{L}=10 \mathrm{~cm}$ ) are shown. A value of $0 \mathrm{Log}$ indicates the value of control plates.

Table 1. Logarithmic decrease of $S$. cerevisiae counts after ozonation treatment throughout the analytical sessions.

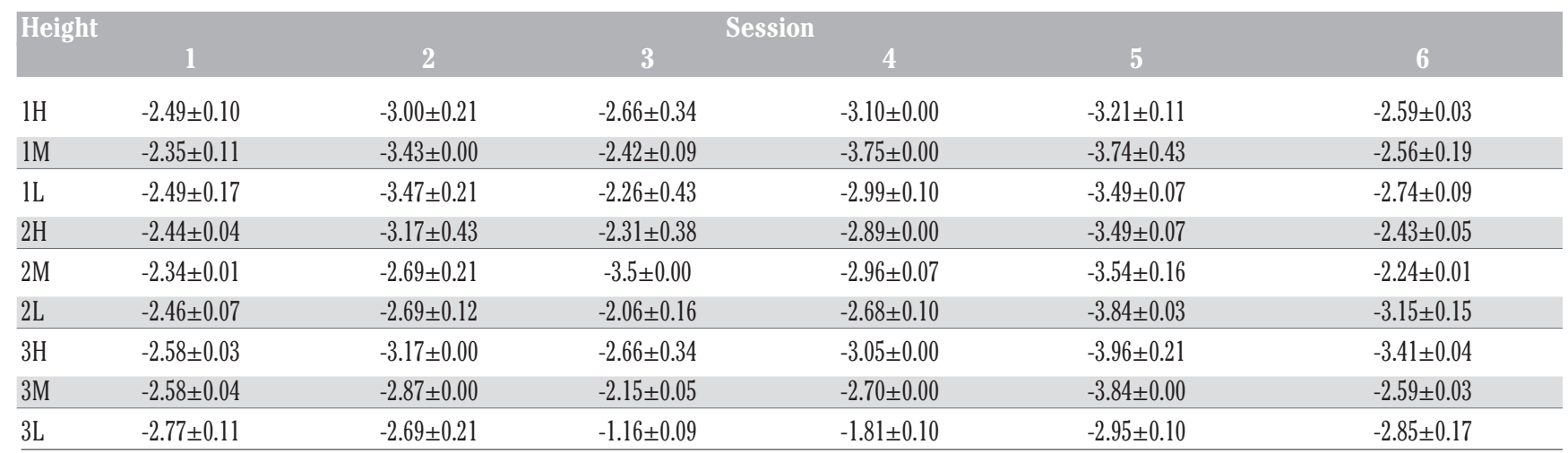

$\mathrm{H}, 270 \mathrm{~cm} ; \mathrm{M}, 110 \mathrm{~cm} ; \mathrm{L}, 10 \mathrm{~cm}$. Values are indicated as mean \pm standard deviation. 
strawberries treated with $0.35 \mathrm{ppm}$ of ozone for 4 days; the development of Botrytis cinerea, Mucor piriformis and Rhizopus stolonifer on grapes was not reduced by a $0.3 \mathrm{ppm}$ ozone treatment for 7 days (Palou et al., 2002) and similar results were obtained with similar tests on apples, blueberries, cranberries and melons (Rice et al., 1982).

These differences in experimental results can be ascribed to the different methodological approaches and to the variable functionality of different ozone generators and distribution systems (De Alencar et al., 2012; Kim et al., 1999, 2003; Serra et al., 2003).

Furthermore, it has to be considered the critical role played by environmental conditions, such as humidity and temperature, on antimicrobial efficacy of ozone, as it is known that also little variations in these parameters can significantly modify its activity.

The natural moulds resistance, due to their cellular constituents, must also be considered in evaluating ozone application; the structure of mould cell wall, unlike bacterial cells, is characterised by a very low lipid content $(<5 \%)$ and it is consequently less susceptible to oxidising agents (Dragoni et al., 1997). In many cases, high doses of ozone are required; for example, Ozkan et al. (2011) observed that the dose needed to remove Penicillium digitatum, Penicillium italicum and Botrytis cinerea from table grapes was also dangerous for workers. Italian legislation allows a maximum exposition dose of $0.1 \mathrm{ppm}$ of ozone within a $8 \mathrm{~h}$ working period, or a $0.3 \mathrm{ppm}$ dose for $\max 15$ min, twice a day (Lgs. Decree $n^{\circ} 81 / 2008$; Italian Republic, 2008).

Considering yeasts, many authors indicated a higher sensitivity to ozone treatments than moulds (Naitoh and Shiga, 1982; Kim et al., 1999), but evident evident variability in ozone susceptibility has been observed among different yeast species (Kim et al., 1999). The efficacy of ozonisation assessed in our study towards Saccharomyces cerevisiae confirmed the results of previous studies and it indicated a marked susceptibility of Saccharomyces spp. to such treatments (Guzzon et al., 2010; Watanabe et al., 2010).

\section{Conclusions}

The results obtained confirm the absolute need for an accurate definition of the treatment conditions with ozone in order to maximise its antimicrobial effect in real working situations, considering the treatment parame- ters (ozone dose and supply modality) in combination with environmental parameters, such as temperature, humidity and air flow.

\section{References}

CNSA, 2010. [Parere del CNSA sul trattamento con ozono dell'aria negli ambienti di stagionatura dei formaggi]. [Paper in Italian]. Comitato Nazionale per la Sicurezza Alimentare Publ., Roma, Italy. Available from: http://www.salute.gov.it/ imgs/C_17_pubblicazioni_1514_allegato.pdf

De Alencar ER, faroni LR, Soares Nde F, da Silva WA, Carvalho MC, 2012. Efficacy of ozone as a fungicidal and detoxifying agent of aflatoxins in peanuts. J Sci Food Agr 92:899-905.

Dragoni I, Cantoni C, Papa A, Vallone L, 1997. [Muffe, alimenti e micotossicosi]. [Book in Italian]. Città Studi Edizioni, Milano, Italy.

Gibson CA, Elliott JA, Beckett DC, 1960. Ozone for controlling mold on Cheddar cheese. Can Dairy Ice Cream J 14:24-8.

Guzzon R, Widmann G, Larcher R, Nicolini G, 2010. Barrel sanitation tests. Industrie delle Bevande 39:15-8.

Italian Republic, 2008. [Attuazione dell'articolo 1 della legge 3 agosto 2007, n. 123, in materia di tutela della salute e della sicurezza nei luoghi di lavoro]. [Regulation in Italian]. In: Official Journal, L 81, 30/04/2008. Available from: http://www.egogw.it/public/about/VIR-0558A-09.pdf

Khadre MA, Yousef AE, 2001. Sporicidal action of ozone and hydrogen peroxide: a comparative study. Int J Food Microbiol 71:131-8.

Khadre MA, Yousef AE, Kim JG, 2001. Microbiological aspects of ozone applications in food: a review. J Food Sci 66:124252.

Kim J-G, Yousef AE, Dave S, 1999. Application of ozone for enhancing the microbiological safety and quality of foods: a review. J Food Protect 62:1071-87.

Kim J-G, Yousef AE, Khadre MA, 2003. Ozone and its current and future application in the food industry. Adv Food Nutr Res 45:167-218.

Laisk A, Kull O, Moldau H, 1989. Ozone concentration in leaf intercellular air space is close to zero. Plant Physiol 90:1163-7.

Moore G, Griffith C, Peters A, 2000. Bactericidal properties of ozone and its potential application as a terminal disin- fectant. J Food Protect 63:1100-6.

Naitoh S, 1993. Studies on the application of ozone in food preservation. Ozone inhibition of yeast. J Antibact Antifungal Agents 21:341-6.

Naitoh S, Shiga I, 1982. Studies on utilization of ozone in food preservation. I. Microbicidal properties of ozone on various microorganisms suspended in water. Journal of Japanese Society of Food Science and Technology 29:1-10.

Ozkan R, Smilanick JL, Karabulut OA, 2011. Toxicity of ozone gas to conidia of Penicillium digitatum, Penicillium italicum and Botrytis cinerea and control of gray mold on table grapes. Postharvest Biol Tec 60:47-51.

Palou L, Crisosto CH, Smilanick JL, Adaskaveg JE, Zoffoli JP, 2002. Effects of continuous $0.3 \mathrm{ppm}$ ozone exposure on decay development and physiological reponses of peaches and table grapes in cold storage. Postharvest Biol Tec 24:39-48.

Pereira APM, Hirsch Werle C, Vinturim Goncalves TM, Hoffmann FL, 2011. Identification and evaluation of antimicrobial resistance of yeast in minimally processed vegetables. Rev Inst Adolfo Lutz 70:139-43.

Perez AG, Sanz C, Rios JJ, Olias R, Olias JM, 1999. Effects of ozone treatment on postharvest strawberry quality. J Agr Food Chem 47:1652-6.

Rice RG, Farquar JW, Bolliky JL, 1982. Review of the applications of ozone for increasing storage times of perishable goods. OzoneSci Eng 4:147-63.

Sarti P, Avigliano L, Görlach A, Brüne B, 2002. Superoxide and nitric oxide-participation in cell communication. Cell Death Differ 9:1160-2.

Serra R, Abrunhosa L, Kozakiewicz Z, Venancio A, Lima N, 2003. Use of ozone to reduce molds in a cheese ripening room. $\mathrm{J}$ Food Protect 66:2355-8.

Staehelin J, Hoigne J, 1985. Decomposition of ozone in water in the presence of organic solutes acting as promoters and inhibitors of radical chain reaction. Environ Sci Technol 19:1206-13.

Watanabe M, Masaki H, Mori T, Tsuchiya T, Konuma H, Hara-Kudo Y, Takatori K, 2010. Inactivation effects of UV irradiation and ozone treatment on the yeast and the mold in mineral water. J Food Protect 73:153742. 